\title{
COOPERATION AND DOING THE BEST ONE CAN
}

\section{By: MICHAEL J. ZIMMERMAN}

Zimmerman, Michael J. “Cooperation and Doing the Best One Can,” Philosophical Studies, 65 (1992): 283-304

Made available courtesy of Springer Verlag.

The original publication is available at www.springerlink.com

***Note: Figures may be missing from this format of the document

\section{Article:}

\section{SETTING THE SCENE}

That one ought morally to do the best one can is a view that enjoys a rich history of support. ${ }^{1}$ Its most famous incarnation is act utilitarianism, according to which one ought to produce the most favorable balance of pleasure over pain that one can. Act utilitarianism is traditionally seen to be an amalgamation of hedonism (the view that the only thing that is intrinsically good [bad] is a state of pleasure [pain]) and consequential- ism (the view that one ought to produce the most favorable balance of intrinsic goodness over intrinsic badness that one can). It is the consequentialist aspect of act utilitarianism that renders it a version of the thesis that one ought to do the best one can.

G. E. Moore is well-known for rejecting hedonism but embracing consequentialism. ${ }^{2}$ There have been many criticisms of Moore's theory. Many of these have been raised by philosophers largely unsympathetic with the view that one ought to do the best one can. But one criticism, raised by C. D. Broad, constitutes an attempt to show that consequentialism doesn't best capture the insight underlying this view. Broad distinguishes between an act's being optimific and its being optimising. ${ }^{3}$ Roughly, an act is optimific just in case the sum intrinsic value of its consequences is greater than the sum intrinsic value of the consequences of any of its alternatives, while an act is optimising just in case the universe is, given the act's performance, better off than it would have been had any of the act's alternatives been performed. ${ }^{4}$ Broad's claim is that Moore, even from his own point of view, should have stated that an act is obligatory just in case it is optimising, not optimific; for this allows for all the value attendant on an act, even non-consequential value, to have a bearing on whether or not the act is obligatory. (Perhaps, for example, an act's being just is a non-consequential value to be attributed to the act; if so, it would be immaterial to the act's being optimific but not to its being optimising. ${ }^{5}$ ) Moore accepted the criticism. ${ }^{6}$

There is reason to think that this criticism does not go far enough. We should distinguish how the universe would be, if an act were performed, from how it could be (in the same sense of "can" that is operative in the view under discussion). Suppose that the universe would be better off if Susan both made and kept a certain promise than it would otherwise be, but also that, were Susan to make the promise, she would in fact not keep it (although she could), and that the universe would be worse off if she made the promise and didn't keep it than it would be if she didn't make the promise at all. All else being equal, Susan's not making the promise is optimising, and yet it is surely plausible to say that, from the perspective that one ought to do the best one can, not making the promise would constitute wrongdoing on her part (for it would not be compatible with rendering the universe as well off as possible). This is a controversial issue, but I would urge that we ought to understand doing the best one 
can, not as doing what is optimising, but rather as doing what is compatible with the universe's being as well off as one can have it. ${ }^{7}$ This interpretation of the view has been best developed by Fred Feldman. Its details need not concern us here. Let me simply say that it is this interpretation of the view that I shall presuppose in what follows. ${ }^{8}$ The view itself I shall put only roughly, as follows (here and henceforth, it is to be understood that $\mathrm{T} 1$ is no later than T2):

(OB) For any person $\mathrm{P}$ and times Ti and T2, P ought at Ti to do at T2 the best that P can at Ti do at $\mathrm{T} 2{ }^{9}$

\section{THE PROBLEM}

While $(\mathrm{OB})$ understood a la Feldman is the best interpretation yet published known to me of the view that one ought to do the best one can, it faces a serious problem, even from the perspective of one sympathetic with the view. It is a problem that has received considerable attention recently owing to the work of Donald Regan. ${ }^{10}$ One simple version of the problem is this. ${ }^{11}$ Suppose that there are two voters, Vincent and Virgil, and two candidates for election, Smith and Jones, and suppose that the voters' options may be ranked according to this matrix:

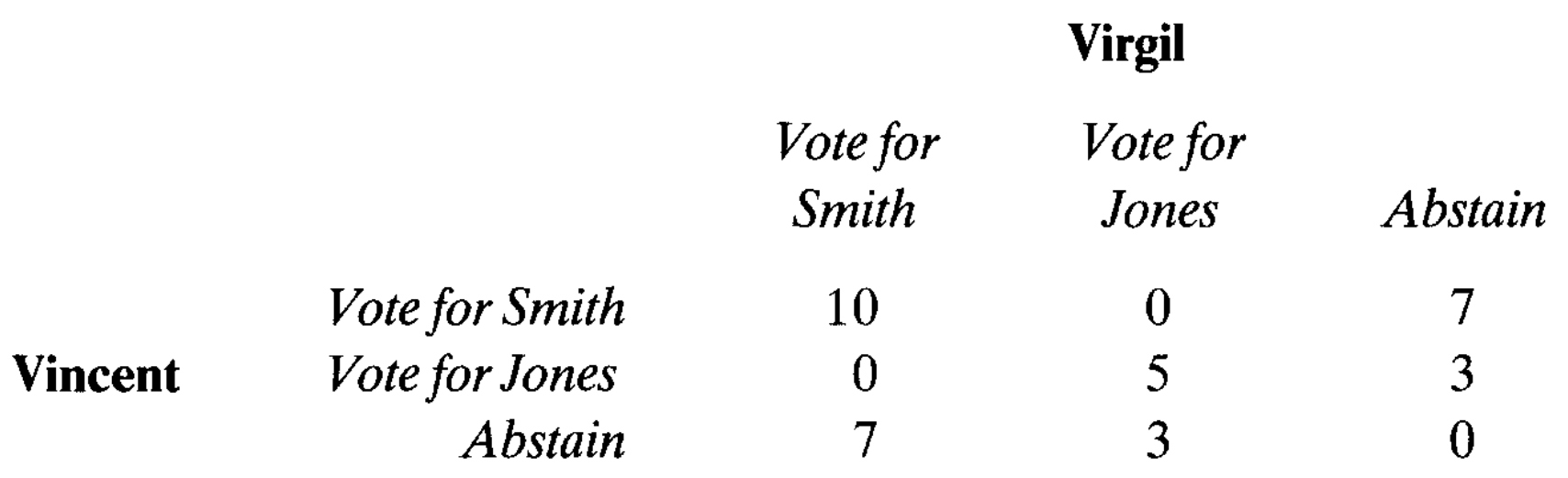

In other words, it would be best (on the Feldman-type understanding of "best" presupposed in (OB)) if both Vincent and Virgil voted for Smith; next best if one voted for Smith and the other abstained; next best if both voted for Jones; next best if one voted for Jones and the other abstained; and worst if either both abstained or one voted for Smith and the other for Jones. The question is: given (OB), what should Vincent and Virgil do?

More information is needed before this question can be answered. Can Vincent act in such a way that Virgil will vote for Smith? If so, (OB) directs Vincent to act in that way and to vote for Smith too. Similarly, mutatis mutandis, for Virgil. Thus there is a scenario in which $(\mathrm{OB})$ is satisfied and in which the best possible outcome (ten units of value) is achieved. ${ }^{12}$ This of course poses no problem for (OB). Nor does this scenario: Vincent can act in such a way that Virgil will vote for Smith (so that, we may say, Virgil is not intransigent relative to Vincent concerning Smith's being unanimously elected), but Virgil can not act in such a way that Vincent will vote for Smith (because Vincent is intransigent relative to Virgil concerning Smith's being unanimously elected; Vincent insists on voting for Jones). Here (OB) directs Vincent to act in such a way that Virgil will vote for Smith and also to vote for Smith himself; but it directs Virgil to vote for Jones (since this is the best he can do, given Vincent's intransigence). It may at first seem odd that (OB) should direct an agent to perform an action which, if performed, 
guarantees that less than the best possible outcome will be achieved (in the sense that ten units of value will be forgone in favor of five), but on reflection this may well seem right. After all, it's not Virgil's fault that voting for Jones is the best he can do, it's Vincent's; it is Vincent who does not do the best he can.

But now notice this. There is a sense in which (OB) seems to allow two wrongs to make a right. Suppose that Virgil is just as intransigently in favor of Jones as Vincent is. Then not only does (OB) direct Virgil to vote for Jones (since this is the best that he can do under the circumstances), it directs Vincent to do this too (since this is now also the best that he can do). Thus, given (OB), neither Vincent nor Virgil does wrong in voting for Jones, even though this yields only five units of value rather than ten; even though, that is, the best that both could do is not done. Somehow, Vincent's intransigently voting for Jones is transformed from being wrong to being right when it is balanced by a matching intransigence on Virgil's part. This implication of (OB) should surely trouble anybody inclined to the view that one ought to do the best one can, inasmuch as it demonstrates that there is a sense in which satisfaction of $(\mathrm{OB})$ is compatible with the best that can be done not being done.

\section{FIRST NON-SOLUTION: UNREQU1TED COOPERATION}

It may seem that the problem has brought to light a limitation to $(\mathrm{OB})$ that is easily remedied. (OB) was drawn up with the individual alone in mind; it ignored the possibility of cooperation. The problem brings this out starkly: through a mutual failure to cooperate, Vincent and Virgil, though doing the best they can singly, ${ }^{13}$ fail to do the best they can jointly. To ensure that they do the best they can jointly, each need only do his part in the mutually cooperative action open to both. Each, that is, need only vote for Smith and the best possible outcome will be assured.

This suggests the following view (labeled "(NS1)" for "Non-Solution $1 ")$ :

(NS1) For any person $\mathrm{P}$ and times Ti and T2, P ought at Ti to do at T2 what P would do at T2 if P's group did at T2 the best that it could at T1 do at T2 (i.e., P ought to "do his or her part"). ${ }^{14}$

Apart from the fact that (NS1) implies that the best is done if everyone acts according to it, it has what may seem to be another attractive feature. It is a common complaint against theories of the sort captured by $(\mathrm{OB})$ that they are too demanding. For instance, $(\mathrm{OB})$ seems to require of each of us that we give and give to charity, since many others will in fact not give and we cannot get them to give (that is, they are intransigent relative to us concerning charity) - although, if everyone were to give, none would have to give very much. (NS1), on the other hand, seems to imply that we each ought to give only that amount which would be required under the counterfactual condition where everyone gives. And this might appear to be just what should be said. Why, after all, should one person be obligated to make up for the moral failures of another?

But this won't do. (NS1) faces a number of problems.

First, a relatively minor problem: (NS1) overlooks the fact that a person may belong to several groups at once. $^{15}$ 
Second, a far more serious problem: (NS1) violates the thesis that "ought" implies "can" (a thesis to which proponents of the view under discussion are committed: one ought to do the best one can). This is illustrated by any case in which one person's doing her part depends on another's doing his, and where this other is intransigent relative to the first person concerning the group's generation of the best possible outcome. For example, my part in generating the best possible outcome may be to enter a room whose door only you can unlock. If you adamantly refuse to do your part, then I cannot do mine. ${ }^{16}$

Third, whatever the best way is to deal with the apparent overdemandingness of (OB) (and let us grant that there is a serious issue here), (NS1) doesn't provide it. The claim, unqualified, that no one should be said to be obligated to make up for the moral failures of another is simply false. (NS1) is too permissive. Just consider a case where all that is needed to prevent a child from dying is the donation of one dollar. There are a hundred people present who can each give one cent; you can give one dollar without any hardship whatsoever; none of the others gives money to the child; and you give one cent, smugly assuring yourself that, in doing your part, you've done your duty. The child dies, of course. Similarly, with reference to the voting case, surely it is in $(\mathrm{OB})$ 's favor that it directs Virgil to vote for Jones, given Vincent's intransigence; for had he voted for Smith, zero rather than five units of value would have been achieved. Such unrequited cooperation does no good at all. ${ }^{17}$

\section{SECOND NON-SOLUTION: PROCEDURAL COOPERATION}

What it seems we want, then, is a theory that will direct Virgil to vote for Jones, given Vincent's intransigence, but which will not permit a similar intransigence on Virgil's part. Donald Regan has produced a very elaborate theory designed to meet this goal. Cutting through the elaboration, we may give this rough version of Regan's proposal:

(NS2) For any person $\mathrm{P}$ and times Ti and T2, P ought at Ti to: hold himself ready at T1 (and up to T2) to cooperate with others at T2; identify prior to $\mathrm{T} 2$ other would-be cooperators at $\mathrm{T} 2$; and (iii) do his part at $\mathrm{T} 2$ in the best action that the group of actual cooperators can at $\mathrm{T} 1 \mathrm{do}$ at $\mathrm{T} 2 .^{18}$

This is an attractive proposal. If everyone follows the prescribed procedure, the best that can be done by all will be done; anyone not prepared to cooperate does wrong; anyone prepared to cooperate but frustrated by other non-cooperators, who nonetheless does his or her best under these less than ideal circumstances, does what he or she ought. Doesn't this capture just what we want to capture?

Unfortunately not. There are two main objections to be made, based on the fact that the proposal prescribes a certain procedure. ${ }^{19}$ First, Regan's theory violates the thesis that "ought" implies "can": P may be unable to do what (NS2) requires. (In particular, P may be unable to identify other would-be cooperators.) Second, Regan's theory ignores the possible costliness of undertaking the specified procedure. ${ }^{20}$ It could be that identifying other would-be cooperators is itself a very costly activity, and to overlook this is surely contrary to the insight underlying the view that one ought to do the best one can. (Here the sort of objection that is so often mistakenly raised against act utilitarianism can be appropriately raised against Regan's theory. The objection against act utilitarianism is this: on many occasions, especially in cases of emergency, there is not enough time to calculate all the relevant utilities as required by act utilitarianism. The proper response on the part of the act utilitarian is that calculating the relevant utilities is itself required by act utilitarianism when and only when doing so maximizes utility — and, presumably, this occurs rarely. But, contrary to act utilitarianism, (NS2) requires that a 
certain procedure always be adopted - even in cases, such as cases of emergency, where it would be particularly costly to do so. Thus here the objection sticks.)

\section{THIRD NON-SOLUTION: (OB) GENERALIZED}

A proposal made prior to Regan's has been resurrected by several others in response to the difficulties that Regan's faces. ${ }^{21}$ It is, in effect, that $(\mathrm{OB})$ be generalized thus:

(NS3) For any persons P1 .. Pn and times T1 and T2, P1 .. . Pn ought at T1 to do at T2 the best that $\mathrm{P} 1 \ldots$. Pn can at $\mathrm{T} 1 \mathrm{do}$ at $\mathrm{T} 2$.

(Where $\mathrm{n}=1,(\mathrm{NS} 3)$ is equivalent to $(\mathrm{OB})$.) This proposal is based on the observation, implicit in the very posing of the problem with $(\mathrm{OB})$, that what several people can jointly achieve may well differ from what any person can singly achieve. For example, given the other's intransigence, neither Vincent nor Virgil can singly achieve ten units of value, but they can jointly achieve this. Thus (NS3) implies that there can be a certain lack of correspondence between individual obligation and group obligation. And it is just this feature of the proposal that some have found attractive and helpful in the attempt to solve the problem concerning intransigence to which $(\mathrm{OB})$ gives rise. Their suggestion is this: ${ }^{22}$ it is not that, where Vincent's intransigence is matched by Virgil, two wrongs have made a right. On the contrary, although (NS3) of course yields the same story about obligation and wrongdoing in the individual case as $(\mathrm{OB})$ does - each of Vincent and Virgil ought to vote for Jones and hence does no wrong in doing so — , unlike (OB), (NS3) still diagnoses a wrongdoing in this case: Vincent and Virgil jointly do wrong in not electing Smith.

This is intriguing but, I believe, unsatisfactory. The problem is simply this: on this account, the group wrongdoing is not attributable to any of the members of the group; neither Vincent nor Virgil can be faulted for

his intransigence. ${ }^{23}$ Suppose that Vincent and Virgil are friends. Virgil sees that Vincent is intransigently in favor of Jones; not wanting to have his friend do wrong, Virgil decides to be intransigently in favor of Jones too, believing that Vincent will thereby be absolved. (He resolves not to listen to entreaties even from Vincent himself; he believes that Vincent, being his friend but subscribing to a theory other than (NS3), may attempt to dissuade him from acting in this way.) Now, if Virgil acts in this way, (NS3) as Virgil recognizes - implies only that Vincent and Virgil jointly do wrong and that neither does singly. But this is too much to swallow; the scenario still smacks of two (individual) wrongs making a right.

I'm not saying that a group's not doing its best must be attributable to all members of the group. Nor am I saying that it must be wholly attributable to any of them. I am saying that, when individuals fail jointly to do their best, this must be at least partly attributable to some of them, so that not all of them can escape the charge of wrongdoing. ${ }^{24}$ This is why I take (NS3) to be a non-solution to our problem.

The proponent of (NS3) might reply in this way. What's wrong with intransigence when it's met with matching intransigence? Given Vincent's intransigence, Virgil's intransigence makes no difference; Vincent's intransigence alone rules out attainment of the group's best. So too, mutatis mutandis, for Vincent's intransigence making no difference. Thus, under the circumstances, there is nothing wrong with the attitude of either. ${ }^{25}$ 
But there is something wrong with this attitude. True, there is a sort of overdetermination here, such that each agent's being a party to achieving less than the best outcome in a way renders the other's being a party to it redundant. Nonetheless, each is a party to it, and no right- thinking conscientious person (someone who seeks clear-headedly to determine what his moral obligation is and to act accordingly) would rest content with being such a party, if he held the view (presupposed here) that moral obligation is a matter of achieving the best possible outcome. We must look elsewhere for a solution to our problem.

\section{FOURTH NON-SOLUTION: COUNTERFACTUAL COOPERATION}

The solution, I believe, is in outline simply (and unsurprisingly) this: one's moral obligation is to do the best one can while avoiding intransigence; that is (to coin a term), one ought transigently to do the best one can. This is in essence Regan's proposal shorn of its objectionable aspect: one must do the best one can (see clause (iii) of (NS2)) while holding oneself ready to cooperate (clause (i)), but there is no obligation to undertake something (identification of cooperators - clause (ii)) that may prove either impossible or damaging.

I have said that I take "doing the best one can" to be understood a la Feldman. ${ }^{26}$ But just what is it to "hold" oneself ready to cooperate"? One proposal is this: to hold oneself ready (that is, to be prepared) to cooperate is simply to be such that one would do one's part if all others did theirs. When conjoined with the injunction to do one's best, this yields the following thesis:

(NS4) For any person P and times Ti and T2, P ought at Ti to:

(i) do at $\mathrm{T} 2$ the best that she can at $\mathrm{T} 1$ do at $\mathrm{T} 2$; and

(ii) be at Ti such that she would do her part at $\mathrm{T} 2$ if all others did theirs.

One problem with (NS4) is that it is too narrow. It overlooks the hypothetical case where not all others cooperate but where a sufficient number do so and their doing so would generate an outcome superior to that generated by $\mathrm{P}$ if $\mathrm{P}$ were to do the best she could in the actual situation. Surely, if we wish to insist on transigence, we wish to have $\mathrm{P}$ prepared to cooperate in the generation of any superior outcome, not just the best possible, so long as this outcome would in fact be the best available (given the behavior of any non-cooperators). Suppose, for example, that there are three agents, Tom, Dick, and Harry, and that the best they can jointly do is to raise and push aside a tree that has fallen on some fourth person.

Suppose also that, if Dick refuses to cooperate with Harry, the best that Tom and Harry can jointly do is to raise the tree so that the victim can crawl out from under it. Suppose finally that, if both Tom and Dick refuse to cooperate with Harry, the best that Harry can do is go for help. What we want is for Harry to be prepared to help raise and push aside the tree if Tom and Dick are prepared to cooperate, and (NS4) gives us that. But what we also want, and what (NS4) does not give us, is for Harry to be prepared to help raise the tree if Tom is prepared to cooperate but Dick is not.

One way to provide what's missing is to amend (NS4) as follows:

(NS4') For any person $\mathrm{P}$ and times Ti and T2, P ought at Ti to:

(i) do at $\mathrm{T} 2$ the best that she can at Ti do at T2; and

(ii) be at Ti such that she would do at $\mathrm{T} 2$ the best that she could at Ti do at T2 no matter what her circumstances might be at $\mathrm{T} 2 .^{27}$ 
There are of course difficulties of interpretation here, but notice how (NS4') would deal with the problem afflicting (NS4). Suppose that neither Tom nor Dick is prepared to cooperate. Then (NS4') is designed to direct Harry to (i) go for help but also (ii) be prepared to cooperate with both Tom and Dick if they are prepared to do so (something that (NS4) also says) and to be prepared to cooperate with Tom alone if Dick is not prepared to do so (something that (NS4) doesn't say).

But (NS4') is nonetheless problematic. The requirement of counterfactual cooperation stipulated in its second clause is too strong. Suppose that $\mathrm{P}$ were force-fed some mind-altering drug. Would he do the best he could under these circumstances? Quite conceivably not (especially if the drug altered his moral perception). Would this show that he was in fact unprepared to cooperate? It would not.

A second problem with (NS4') is that it is not clear whether it conforms with the thesis that "ought" implies "can." While it is of course always in one's power to do the best one can, is it always in one's power to be such that one would do the best one could if circumstances were different? I'm not sure how this question should be answered, but this much can be said: an acceptable solution to our problem, if it is to conform with the original insight that underlies (OB), must leave no doubt as to whether it conforms with the thesis that "ought" implies "can."

\section{FIFTH NON-SOLUTION: COOPERATION AS INVOLVING MERE OPENNESS}

One attractive suggestion that meets this requirement is to view transigence as openness, where this is understood as follows (where T1 is no later than T2, as before, and T2 is no later than T3):

(D1) $\mathrm{P}$ is open at Ti to $\mathrm{Q}$ concerning $\mathrm{X}$ at $\mathrm{T} 3=\mathrm{df}$. $\mathrm{Q}$ can at Ti so act at T2 that $\mathrm{P}$ contributes at T3 to $\mathrm{X}^{28}$

(Q may be an individual or a group of individuals.) We could then say:

(NS5) For any person $\mathrm{P}$ and times Ti and T2, P ought at Ti to:

(i) do at $\mathrm{T} 2$ the best that $\mathrm{P}$ can at $\mathrm{Ti}$ do at $\mathrm{T} 2$; and

(ii) for any group of persons $G$ and outcome $X$, be open at Ti to G concerning $X$ at $T 2$ iff $\mathrm{P}$ and $\mathrm{G}$ bringing about $\mathrm{X}$ is the best that $\mathrm{P}$ and $\mathrm{G}$ as a group can at Ti do at $\mathrm{T} 2$.

The reason why this meets the requirement concerning "ought" and "can" is this. In general, one way in which a person $\mathrm{P}$ can see to it that some other(s) Q can so act that he $(\mathrm{P})$ does some act $\mathrm{A}$ is simply by doing A; if Percy raises his hand, then it is trivially true that Quincy can so act that Percy raises his hand. Thus, one way in which $\mathrm{P}$ can see to it that $\mathrm{Q}$ can so act that $\mathrm{P}$ contributes to $\mathrm{X}$ is simply by contributing to $\mathrm{X}$. Now, in the case where $\mathrm{P}$ and $\mathrm{G}$ as a group can bring about $\mathrm{X}, \mathrm{P}$ can always do his part (i.e., contribute to $X$ ) if those in $G$ do theirs. And since those in $G$ can always do theirs if $P$ does his, it follows that $\mathrm{P}$ can be open to $\mathrm{G}$ in the way that (NS5) prescribes; that is, he can so act that G can so act that he $(\mathrm{P})$ contributes to $\mathrm{X}$.

Moreover, (NS5) avoids the severity of (NS4') in that it requires simply that others can have P cooperate and not that $\mathrm{P}$ would cooperate no matter what the circumstances. Like (NS4'), though, (NS5) aims to satisfy, as (NS4) did not, the requirement that P's preparedness to cooperate be general. 
Nonetheless, (NS5) faces serious problems. First, it still does not fully meet the requirement that P's preparedness to cooperate be general, for two reasons. It fails to stipulate that $\mathrm{P}$ be prepared to cooperate when others cooperate. It could be that $\mathrm{P}$ is prepared to do his part if, but only if, not all others do theirs. ((NS5) requires, as (NS4) did not, that Harry be prepared to do his part in contributing to the best that Tom and Harry can achieve without Dick's cooperation, but it doesn't require — although it should that Harry be prepared to do this when Tom does his part.) Also, (NS5) requires only that P be open to G concerning the best that $\mathrm{P}$ and $\mathrm{G}$ can bring about. Yet it seems that $\mathrm{P}$ should be required to be prepared to do whatever $\mathrm{G}$ agrees to do, so long as this is superior to what $\mathrm{P}$ alone can do. (Suppose that, although the best that Tom, Dick, and Harry can do is to raise and push aside the tree, all that Tom and Dick are prepared to do with Harry is to raise the tree without pushing it aside, and that this would be better than Tom's and Harry's doing this without Dick's help. Then Harry should be prepared to do his part in raising (but not pushing aside) the tree with Tom and Dick, and yet (NS5) fails to require this.)

Second, although (NS5) is superior to (NS2) in that it conforms with the thesis that "ought" implies "can," like (NS2) it ignores the possible costliness of doing what is required. Even mere openness can be costly, as when, for example, P's openness to $\mathrm{G}$, having become public knowledge, prompts someone else to perform a harmful act that would otherwise not have been performed.

Third, (NS5) can in certain cases issue in an unacceptable dilemma. It has been noted that one way in which $P$ can see to it that $G$ can so act that $P$ contributes to $X$ is simply by contributing to $X$. What if this is the only way in which $\mathrm{P}$ can see to this? For example, suppose that Vincent and Virgil are both going to vote for Jones and that each is closed (i.e., not open) to the other concerning Smith's being unanimously elected simply because they live at different ends of the country and cannot interact. Here it is the mere fact that Vincent is going to vote for Jones that makes it the case that he is closed to Virgil concerning Smith's being unanimously elected. (So too, mutatis mutandis, for Virgil's being closed to Vincent.) Vincent's being closed to Virgil in this regard is due, not to any orneriness on Vincent's part, but simply to the mutual disconnectedness of Vincent and Virgil. Now, (NS5) condemns even such closedness, but this is too sweeping; for notice that it also condemns, under the circumstances, Vincent's voting for Smith (since, given Virgil's closedness, this is not the best he can do). In such a case, (N55) issues in a dilemma: clause (i) requires Vincent to vote for Jones, but clause (ii) requires Vincent to be open to Virgil concerning Smith's being unanimously elected, and this can be achieved by Vincent only if he doesn't vote for Jones (but votes for Smith instead).

Perhaps this result should not surprise us. If Vincent and Virgil are wholly disconnected in this way, then, even if there is a sense in which they as a group could bring about Smith's being unanimously elected, this hardly seems to be a paradigmatic case of joint action. On the contrary, it seems to be a case of disjoint action happening to yield a certain outcome. There is a sense, then, in which the failure to elect Smith is a failure to achieve the best outcome available to the group of Vincent and Virgil, but in this case it is not a genuinely joint failure and there is therefore no need to think that the failure should be attributable even in part to some member of the group. If anything, it is "attributable to nature." 29

\section{PROPOSED SOLUTION: TRANSIGENCE AND CONNECTEDNESS}

In order to solve the first part of the first problem with (NS5) and thus ensure that P be prepared to cooperate when others cooperate, let us slightly revise our account of what transigence consists in and understand it, not in terms of mere openness, but as follows: 
(D2) $\mathrm{P}$ is transigent at $\mathrm{T} 1$ relative to $\mathrm{Q}$ concerning $\mathrm{X}$ at $\mathrm{T} 3=\mathrm{df}$. $\mathrm{Q}$ can at $\mathrm{T} 1$ so act at $\mathrm{T} 2$ that $\mathrm{Q}$ and $\mathrm{P}$ as a group contribute at $\mathrm{T} 3$ to $\mathrm{X}$.

The second part of the first problem may be handled by stipulating that $P$ be transigent relative to $G$ concerning any $\mathrm{X}$ which $\mathrm{P}$ and $\mathrm{G}$ can bring about and which is superior to what $\mathrm{P}$ can in fact bring about.

The second problem may be handled by stipulating that transigence is required of P only if it does not diminish the value of P's doing her best.

The third problem concerning disconnectedness requires somewhat fuller treatment. Consider Vincent and Virgil again, and think of them again as disconnected. Vincent can so act that Vincent votes for Smith, and Vincent can so act that Vincent doesn't vote for Smith; unfortunately, while Virgil can so act that he and Vincent fail as a group unanimously to elect Smith, he cannot so act that he and Vincent do as a group unanimously elect Smith. Thus Vincent is intransigent relative to Virgil concerning Smith's being unanimously elected. But, again, this is no fault of Vincent's (but a "fault" of nature's); due to their mutual disconnectedness, Vincent must be intransigent relative to Virgil concerning some potential group outcomes. In particular, Vincent cannot so act that both Virgil can so act that they do as a group unanimously elect Smith and Virgil can so act that they fail as a group unanimously to elect Smith. In general, then, we should insist on transigence only where there is connectedness, which may be defined as follows (where T1 is no later than T2 and ... and T4 is no later than T5, and where T2 is earlier than T4):

(D3) $\mathrm{P}$ is connected at Ti to $\mathrm{Q}$ with respect to $\mathrm{X}$ at T5 $=\mathrm{df}$. $\mathrm{P}$ can at Ti so act at T2 that both (i) $\mathrm{Q}$ can at $\mathrm{T} 3$ so act at $\mathrm{T} 4$ that $\mathrm{Q}$ and $\mathrm{P}$ as a group contribute at $\mathrm{T} 5$ to $\mathrm{X}$, and (ii) Q can at T3 so act at T4 that $\mathrm{Q}$ and $\mathrm{P}$ fail as a group to contribute at T5 to $\mathrm{X} .^{30}$

Where there is connectedness, what Q can see to with respect to P's contributing to $\mathrm{X}$ is up to P. The ball is thus in P's court, and for this reason P is in a position to put it in Q's court. Consider Vincent and Virgil once again, but now think of them as mutually connected. Vincent's being connected to Virgil with respect to Smith's being unanimously elected consists in this: Vincent can act in such a way that it is left up to Virgil whether both of them vote for Smith. (How? This will of course depend on further details of the case. (D3) itself includes no stipulation as to just how P should act at T2 (or Q at T4, or P and Q at T5). Perhaps Vincent can simply inform Virgil — truthfully — that he will comply with Virgil's wish, if he does so wish, that Smith be unanimously elected.) That Vincent can act in this way is, of course, no guarantee that he will. While disconnectedness ensures lack of influence, connectedness doesn't ensure influence. If Vincent opts for intransigence concerning Smith's being unanimously elected, then, even though he is connected to Virgil with respect to Smith's being unanimously elected, Virgil cannot influence Vincent in this regard and so Virgil's access to the best that is jointly achievable is effectively obstructed by Vincent. This is Vincent's fault; because of his being connected to Virgil, his intransigence is not "attributable to nature."

The revision of $(\mathrm{OB})$ that I now propose in light of these considerations is this:

(OBrev) For any person $\mathrm{P}$ and times Ti and T2, P ought at Ti to: 
(i) do at $\mathrm{T} 2$ the best that $\mathrm{P}$ can at $\mathrm{T} 1$ do at $\mathrm{T} 2$ (call whatever act this happens to be act $\mathrm{A}$ ); and

(ii) for any group of persons $G$ and outcome $X$ such that $P$ is connected at $T 1$ to $G$ with respect to $X$ at $T 2^{31}$, be transigent at Ti relative to $G$ concerning $X$ at $T 2$ if

(a) $\mathrm{P}$ and $\mathrm{G}$ as a group can at Ti bring about $\mathrm{X}$ at $\mathrm{T} 2$,

(b) P and $\mathrm{G}$ as a group bringing about $\mathrm{X}$ at T2 is better than P doing A at T2, and

(c) P's being transigent at $\mathrm{T} 1$ relative to $\mathrm{G}$ concerning $\mathrm{X}$ at $\mathrm{T} 2$ conjoined with $\mathrm{P}$ 's doing A at T2 is no worse than P's simply doing A at T2.

Some comments are in order.

First, (OBrev) is oversimplified in that it fails to account for the possibility that there may be several independent ways in which $\mathrm{P}$ can do her best (rather than just one, namely, A) and for the possibility that there may be several independent ways in which $\mathrm{P}$ and some group $\mathrm{G}$ as a group can do something better. ${ }^{32}$ I shall forgo modification of (OBrev) to meet these possibilities; it is easy to provide but, for present purposes, would make (OBrev) unnecessarily complicated.

Second, clause (ii), like clause (i), satisfies the thesis that "ought" implies "can." (Transigence is called for only where there is connectedness.) This aspect of (OBrev) is of course crucial to its claim to accommodate the insight underlying the view that one ought to do the best one can. Here it is pertinent to note that, while (OB) implies that it is only what one does that counts (with respect to acting as one ought), (OBrev) implies that how one does it counts as well. Not only must one do one's best, one must do it transigently. In this respect, (OBrev) appears to accord with Regan's claim that a satisfactory solution to our problem must involve a theory that is not "exclusively act-oriented," where (it seems) a theory is exclusively act-oriented just in case one's satisfying it depends solely on whether (and not on how) one performs some act. ${ }^{33}$ Even so, (OBrev) is not simply a theory that tacks an evaluation of the agent's character on to an evaluation of her act. It does combine act-evaluation with attitude-evaluation, but the attitude in question is in the agent's control just as the act is. (In)transigence (where there is connectedness) is a voluntary stance; it is optional. (OB) is of course silent on this question of attitude; (OBrev) is not - it requires transigence. Sometimes this difference between them will issue in a difference in what actions are required. This is so in the case where Vincent and Virgil are connected. Whereas (OB) implies that both do as they ought if they intransigently vote for Jones, (OBrev) implies that both do as they ought only if they transigently vote for Smith. ${ }^{34}$

Third, subclause (b) is designed to satisfy fully the requirement that P's preparedness to cooperate be general. It may seem that this sub- clause is not adequate for the following reason. Suppose that Tom and Dick can rescue ten people on the left and that Tom and Harry can rescue five people on the right, that the former would be better than the latter, and that not both group actions can be performed. Does (OBrev) require Tom to be transigent concerning both rescues and, if so, is this not objectionable? The answer is: yes, it does and, no, it isn't. It is a mistake to concentrate just on the groups of Tom and Dick and of Tom and Harry. There is, after all, the group of Tom and Dick and Harry. Now, Tom and Dick and Harry as a group can rescue either the ten, or the five, but not both. but this presents no problem, for the incompatibility of these actions does not render it impossible for Tom to be prepared to do whatever the group of Tom and Dick and Harry is prepared to do. (This applies even in the minimal case where Tom is connected to each of Dick and Harry concerning the respective rescues but where there is no other connectedness.) 
Fourth, the dilemma generated by (NS5) is avoided by (OBrev), since (D3) implies that P's not doing her part does not itself imply that $\mathrm{P}$ is intransigent relative to some connected other(s) concerning what is group best. Indeed, if she doesn't do her part but is not intransigent, then this must be because Q has failed to see to it that she does her part. By being transigent, P puts the ball in Q's court; and so, by failing to act so that the best that $\mathrm{P}$ can do is to contribute to $\mathrm{X}$, it is $\mathrm{Q}$, and not $\mathrm{P}$, who does wrong.

Fifth, where a group has no connected members, such that any group action must be a mere assemblage of disjoint individual actions, it can happen that the group will fail to do its best without any individual doing wrong. This is where (OBrev), in avoiding the dilemma generated by (NS5), differs from (NS5). Here a group failure is not attributable to any individual failure, precisely because joint action is ruled out. And here, in contrast with (NS3) (the generalized version of (OB)), I would diagnose no wrongdoing whatsoever, not even by the group. Such a group is not a genuine moral entity and it would be misleading to ascribe to it the capability of doing either right or wrong (although, I concede, there is a sense in which it can do good or bad). ${ }^{35}$ Thus I would seek to preserve the notion that all wrongdoing is ultimately individual wrongdoing.

Sixth, if everyone other than $\mathrm{P}$ does her part in producing the best that is jointly achievable, then $\mathrm{P}$ can certainly do no wrong in doing her part too, for she can do no better. But ought she to do her part? As long as we construe "contribute" as liberally as we have so far been doing, so that she also contributes who only lets others get on with what they're doing, the answer is yes. ${ }^{36}$ But it is not the case that P must always actively contribute to the achievement of the best possible outcome. There are three cases where her remaining idle in this regard is permissible. First, it may be that she cannot actively contribute to the outcome. Second, it may be that, while she can actively contribute to some outcome, she ought nonetheless to remain idle, because only in this way can the group achieve its best. (If Rachel is a superior swimmer to Roberta and Roberta's joining in a rescue would only mess things up, then Roberta ought to stand by while Rachel rescues a drowning man.) Third, it may be that $\mathrm{P}$ is permitted a choice as to whether to remain idle, because there are more than enough people actively contributing to the groupbest and her active contribution, while not counterproductive, would not help either. In this last sort of case, if $\mathrm{P}$ does not contribute actively to the outcome, she gets a sort of free ride; the best is achieved without any effort on her part. Such free- riding seems to me unobjectionable, though, if accompanied by the transigence that $(\mathrm{OBev})$ requires.

Finally, we should ask: what claim does (OBrev) have to being the theory that those who have proposed (OB) have really been looking for all along? ${ }^{37}$ My answer is that someone who is sympathetic with the thesis that one ought to do the best one can should find fault with any individual who obstructs anyone else's access to the best possible outcome. This is why intransigence is to be proscribed, and this is why a simple generalization of (OB) along the lines of (NS3) is not satisfactory. Note that (OBrev) does not condemn simply impeding another's options; after all, one can hardly ever avoid doing this. It doesn't even condemn preventing someone else from doing the best she could otherwise singly do; if Rachel is a superior swimmer to Roberta, there is nothing wrong (ceteris paribus) with Rachel's firmly intending to rescue the man, even though this prevents Roberta from doing so and even if Roberta's doing so is the best that Roberta could otherwise achieve on her own. What it does condemn is one person's obstructing another's access to the best that is jointly achievable, and it condemns this only in the sense of being intransigent concerning what is group- best, and not in the sense of doing something incompatible with what is group-best. (Virgil does not do wrong in voting for Jones, given Vincent's intransigence 
concerning Smith's being unanimously elected, even though his so doing is incompatible with the best that is jointly achievable, namely, Smith's being unanimously elected.) Of course, it is true that doing what is incompatible with what is group-best precludes any further transigence concerning what is group-best; but it does not preclude prior transigence. (When Virgil votes for Jones, he can no longer be transigent concerning Smith's being unanimously elected ${ }^{38}$; but, prior to so voting, although his so voting is even as of that earlier time the best that he can in fact do, he must be transigent relative to Vincent concerning Smith's being unanimously elected.)

\section{AN OBJECTION}

I have said that $(\mathrm{OB})$ is "exclusively act-oriented" while (OBrev) is not. I have also said that this is to the latter theory's credit. But here the following objection may be raised. The switch from (OB) to (OBrev) is not called for. (OB) can accommodate the requirement concerning transigence as long as it is acknowledged that, in any situation, the best that one can do is to perform some act transigently. In other words, transigence is just one of the features of (and thus just one of the features that contributes to the value of) what one does and is simply to be included in the calculus of values along with all the other value-contributory properties of actions (whatever they may be). Given the rejection of consequentialism and the admission of nonconsequential values to this calculus, there is no reason to exclude transigence from it.

This objection raises deep and difficult issues in action-theory. Is it in general true that doing A X-ly constitutes performing some other, more complex action B? In particular, is doing A transigently just to do something else B, something which may (or may not) be appropriately described as "doing the best one can"? If the answer is no, the objection fails; if it is yes, then it would seem to succeed. What is the correct answer?

Fortunately, I don't think that the answer need be given here. Rather, all that needs to be said is this. Hitherto, in this paper and apparently in the writings of others, it has been presupposed that doing A transigently is not just to do something else B. (Certainly both Regan and Feldman appear to accept this presupposition.) Given this presupposition, I propose (OBrev) as the correct criterion of what it is to act as one ought. On the other hand, if this presupposition is rejected, I see no reason not to revert to (OB), as long as this is supplemented with the stipulation that transigence (as spelled out in clause (ii) of (OBrev) is a necessary feature of the best alternative open to an agent. ${ }^{39}$

\section{NOTES}

1. Here I intend "ought" to express obligation, which is to be contrasted with wrongdoing, rather than to express an ideal, which is simply to be contrasted with the failure to live up to that ideal. Many of the points that I raise in this paper, however, would hold even on the latter interpretation of "ought."

2. See [12].

3. [3], pp. 48-9.

4. Actually, Broad allows for the possibility of ties in value in his characterization of "optimific" and "optimising." This allows for an act's being right, because optimific or optimising, but not obligatory.

5. Cf. [5], pp. 50-2. Such an observation begins to undermine the traditional distinction between consequentialism and deontology.

6. [11], pp. 559-60. 
7. See [24] for a discussion of this issue.

8. See [5], p. 38. Actually, I would urge a slight revision of Feldman's view, one that doesn't require that the value at issue be intrinsic, so that even such non-utilitarians as W. D. Ross (in [16]) may be seen to embrace the view that one ought to do the best one can. (For Ross, the "best" will be understood in terms of which prima facie obligation is most stringent.) This undermines even further the traditional distinction between consequentialism and deontology. See [23], pp. 66 and 74n.3.

9. A somewhat fuller rendition would include the clause "and this is all that $\mathrm{P}$ ought at $\mathrm{Ti}$ to do at T2." (OB) is thus intended to say that $\mathrm{P}$ ought to do something if and only if it is the best that $\mathrm{P}$ can do. For simplicity though, I shall not include such an extra clause in the formulae that follow.

10. See [15]. The problem is anticipated in [2], [6], and [20] (cited in [15], p. 232, notes 7 and 8).

11. Here I am borrowing from [15], p.18 and [5], p. 155.

12. Regan argues correctly ([15], pp. 52-5) that act utilitarianism is always consistent with producing the best consequence possible. Similarly, (OB) is always consistent with achieving the best outcome possible.

13. Here and henceforth, when I say that two (or more) people do the best they can singly, I mean simply that each does the best he can in fact do under the circumstances. I don't mean that each does the best he can do "all on his own," i.e., bracketing any cooperation from others. And so, if full cooperation is in fact forthcoming, the best that two (or more) people can do singly will in fact be to do whatever it is that they would do if they were to do the best they could jointly.

14. Cf. [15], p.85 on what Regan calls COP.

15. Cf. [5], p. 153.

16. Cf. [5], p. 165.

17. Cf. [7], p. 29. "Cooperation" ought perhaps to be put in quotes here, since it must fail. (Cf. [15], p. 126ff. on what goes into complete cooperation.)

18. [15], pp. 135-6.

19. See [1], pp. 157-9; [4], pp. 422-3; and [5] pp. 171-3. Regan responds to such criticism ([15], p. 169ff.), but the response seems unsatisfactory.

20. Regan deliberately ignores this ([15], p. 176ff.).

21. Originally: [14], p. 51 (and see also [10], p. 317). Later: [4], pp. 422-3; [5], p. 161; [8], p. 100ff.; [13], p. 73; and [22], p. 109.

22. See [5], p. 177 and [8], p. 100.

23. Here "faulting" someone means ascribing wrongdoing to that person. Thus "attributing" a group wrongdoing to an individual involves finding that that individual has done wrong with respect to the group outcome in question. It is natural to use the phrase "P is responsible for $\mathrm{X}$ " instead of the phrase " $\mathrm{X}$ is attributable to $\mathrm{P}$," but one should be wary of this. At least, one should not take wrongdoing itself to suffice for culpability. Cf. [21], pp. 41-3.

24. Cf. [15], p. 131 and [18], p. 81. I stress joint failure in achieving the best. As will be seen in Section 7, I allow for the possibility that there be a sort of disjoint failure to achieve a group-best outcome that involves no wrongdoing on anyone's part.

25. See [5], p. 177.

26. But see note 8 above.

27. Cf. [18], p. 85 for a similar proposal concerning compliance with a policy.

28. Contribution, in the present sense, may be passive. He also contributes who only lets others get on with what they're doing.

29. This is an ironic use of "attributable." Nature can do no wrong. See note 23 above. 
30. Two important points. First, notice that the time, T2, of P,s act is earlier than that, T4, of Q,s act. We must insist on transigence on P's part only up until that time (T4) when Q plays his hand. If at T4 Virgil votes (irrevocably) for Jones, we must not insist that Vincent still be transigent at T4 concerning Smith's being unanimously elected (after all, he cannot any longer be so transigent). Second, clause (ii) of (D3) is to be so understood that, if just one of Q and P fails at T5 to contribute to $\mathrm{X}$, then $\mathrm{Q}$ and $\mathrm{P}$ fail as a group at T5 to contribute to $\mathrm{X}$.

31. Note that this requires (given the relation between T2 and T4 in (D3) - see note 30 above) not just that $\mathrm{T} 1$ be no later than $\mathrm{T} 2$, but that the former in fact be earlier than the latter.

32. Cf. note 4 above.

33. [15], pp. 113-5.

34. Why for Smith and not for Jones? Because, if Vincent is transigent concerning Smith's being unanimously elected, then Virgil can so act that Smith is unanimously elected; hence Virgil would not do his best by voting for Jones. So too, mutatis mutandis, for Virgil's being transigent in this regard. Cf. note 12 above.

35. Cf. [19], p. 342 and pi, p. 27.

36. See note 28 above. Of course, there may be several ways in which $\mathrm{P}$ can do her part. See the first comment on (OBrev) above.

37. Cf. [15], p. xii.

38. See note 31 above.

39. An earlier version of this paper was presented in February 1990 to the members of the Department of Philosophy at the University of North Carolina at Greensboro and at a meeting in Chapel Hill of the Research Triangle Ethics Circle. I am grateful to all those who provided comments on those occasions and especially wish to thank Thomas E. Hill, Sr., Joshua Hoffman, Jarrett Leplin, Terrance McConnell, Gerald Postema, Andrews Reath, Geoffrey Sayre McCord, and Lynne Tirrell. I also wish to thank Roderick Chisholm, Ishtiyaque Haji, and Terrance McConnell for comments made on other occasions. I am grateful, too, for the extensive and probing comments of an anonymous referee.

Writing of this paper was aided by a Summer Excellence Research Award received in 1989 from the University of North Carolina at Greensboro.

\section{BIBLIOGRAPHY}

1. Barley, Blake. Review of [15]. Noûs, 18 (1984): 152-9.

2. Barnes, Gerald. "Utilitarianisms." Ethics, 82 (1971); 56-64.

3. Broad, C. D. "Certain Features in Moore's Ethical Doctrines." In [17]: 41-67.

4. Conee, Earl. Review of [15]. Journal of Philosophy, 80 (1983): 415-24.

5. Feldman, Fred. Doing the Best We Can. Dordrecht: D. Reidel, 1986.

6. Gibbard, Allan. "Rule-Utilitarianism: Merely an Illusory Alternative?" Australasian Journal of Philosophy, 43 (1965): 211-20.

7. Humberstone, I. L. "The Background of Circumstances." Pacific Philosophy Quarterly, 64 (1983): 19-34.

8. Jackson, Frank. "Group Morality." In Metaphysics and Morality, edited by Philip Pettit, Richard Sylvan, and Jean Norman (Oxford: Basil Blackwell, 1987): 91110.

9. McConnell, Terrance C. "Interpersonal Moral Conflicts." American Philosophical Quarterly, 25 (1988): 25-35.

10. McKinsey, Michael. "Obligations to the Starving." Noûs, 15 (1981): 309-23.

11. Moore, G. E. "A Reply to My Critics." In [17]: 535-677. 
12. Moore, G. E. Ethics. Oxford: Oxford University Press, 1965.

13. Parfit, Derek. Reasons and Persons. Oxford: Clarendon Press, 1984.

14. Postow, B. C. "Generalized Act Utilitarianism." Analysis, 37 (1977): 49-52.

15. Regan, Donald H. Utilitarianism and Co-operation. Oxford: Clarendon Press, 1980.

16. Ross, W. D. The Right and the Good. Oxford: Clarendon Press, 1930.

17. Schilpp, Paul Arthur, ed. The Philosophy of G. E Moore. Evanston: Northwestern University, 1942.

18. Schwartz, Thomas. "Dr. Krankheit and the Concept of Compliance." American Philosophical Quarterly, 22 (1985): 81-7.

19. Smith, Holly M. "Moral Realism, Moral Conflict, and Compound Acts." Journal of Philosophy, 83 (1986): 341-5.

20. Sobel, Jordan Howard. "Rule-Utilitarianism." Australasian Journal of Philosophy, 46 (1968): 146-65.

21. Zimmerman, Michael J. An Essay on Moral Responsibility. Totowa: Rowman and Littlefield, 1988.

22. Zimmerman, Michael J. "Lapses and Dilemmas." Philosophical Papers, 17 (1988): 103-12.

23. Zimmerman, Michael J. "Subsidiary Obligation." Philosophical Studies, 50 (1986): 65-75.

24. Zimmerman, Michael J. "Where Did I Go Wrong?" Philosophical Studies, 58 (1990): 83-106. 